\title{
Construction of Archives Culture and Development of Archives Information Resources
}

\author{
Qun Li \\ Jilin Agricultural University, Changchun of China \\ Liqun1968@126.com
}

Keywords: Archives; Cultural construction; Information resources; Development and; Utilization

\begin{abstract}
The value of archives is very valuable, because it records a lot of data, and the high degree of real data, and more importantly, archives resource has very high cultural value. The rational use of cultural resources of archives in the process of social development, can promote the cultural resources of archives to serve the society, promote archives cultural values revealed in this paper. The concept of culture from the cultural construction archives establishment, cultural innovation and cultural construction of publicity, through comprehensive analysis, put forward the construction of archive culture exists in the development and utilization of archival information resources in the problem, and promote the development and utilization of the archives information resources in the process of the construction of Archives Culture Emphasis.
\end{abstract}

\section{The Construction of Archives Culture}

\section{The Current Situation of Archives Culture Construction}

Archives culture is a complete cultural system of ${ }^{[1]}$, with the archive consciousness as the core, the consciousness of Archives under the guidance of the behavior and the formation of materialization part, constitute a complete cultural system. Based on this theory, put into practice, the author thinks the construction of archive culture can be divided into three systems, namely: Archives of endogenous cultural system, behavior culture system construction and archives archives cultural achievements and exogenous cultural system construction in new period. The development of archives in China showing a thriving scene, archives culture construction has achieved fruitful results, but in the face of the development of information technology, resources and Archives The development of archives culture should be combined with the development of archives culture so as to correctly treat the relationship between the two, and make full use of the concept and consciousness of archives culture construction to speed up the utilization efficiency of archives information resources.

\section{Concept of Archives Culture Construction}

The cultural attribute of archives to archives culture construction is the momentum in the development of archives, archives is the duty of the historic mission and responsibility. Only to establish the archives culture concept, will once again usher in the development of archives as spring . archives, to study and implement Scientific Outlook on Development, deeply understand the significance of the implementation of the strategy of cultural construction of archives. To fully understand the new situation of basic construction of archives culture connotation, features and characteristics of the times, "responsible for the history, reality, high sense of responsibility for the future", to further enhance our cultural consciousness, establish archives culture science Read, to strengthen and promote the construction of archives culture to provide a strong ideological guarantee.

\section{The Innovation of Archives Culture Construction}

In the cultural and creative industries, before practice innovation often walk in the theoretical research, the domestic and foreign archives, practice departments of public cultural museums and libraries for the development of archives of China's cultural and creative industry brings many new enlightenment of strengthening innovation culture construction process in the ${ }^{[3]}$. file, the use and development of Archives information resources in the full use of innovative concept of archives 
culture, strengthen the efficiency and efficiency of development and utilization of archival resources, the use of data, systematic and personalized archives resource utilization, improve the construction of archives management.

\section{Problems Faced by the Development and Utilization of Archival Information Resources}

\section{The Lack of Awareness of Archives Resources Development}

The ideological concept has not been completely change ${ }^{[4]}$. at present, in many departments or units of the staff thought, on one hand the archives information consciousness behind. Not to file information as the unique value of the information resources, development and utilization; not the archives department as the collection, sorting, identification, development and utilization of the archives information exchange base, better in the service economy. On the other hand, the open exchange of ideas behind. Due to the "heavy hidden light", "confidential insurance,

The use of dangerous "the shackles of backward ideas, can not correctly handle the archival information" Tibet "and" use ", the dialectical relationship between security and open open, exchange, sharing less than ${ }^{[5]}$. at the same time, there are benefits of service concept behind the problem. Due to lack of collection equipment, backward and other reasons, resulting in the archives of the precision. The recall is low, thus affecting the consolidation utilization and the benefit of the information resources of archives resources.

\section{The Quality of Archives Staff is Limited}

The quality of archivists archives staff including theoretical level and practical work ability, foreign language level and the computer as the representative of modern equipment comprehensive application ability of ${ }^{[6]}$. archives management personnel with only the original knowledge, skills and experience to complete the work, which cannot adapt to the development trend of the world science and technology change rapidly, also can not adapt to the new situation facing the development of society. Especially the archives management personnel lack of computer knowledge and knowledge of the Internet development, also hinder the archives information resources.

\section{The lack of Integration Development System}

The library information resources of internal resources more, the staff should be based on mutual assistance to complete the basic management work of ${ }^{[7]}$. but the coordination of the work of library management is not enough, did not form a good internal management method, can not be students in the library and book work should be relative, occurring phenomenon makes the loss of a large number of library resources; second, some of the books resources need to focus on management, but effectively classified and distinguished workers did not, the lack of management skills.

\section{The Main Measures of Information Resources Integration and Development and Utilization of the Archives of the University Library}

\section{To Strengthen the Construction of Archives Culture System and Regulations}

To strengthen the construction of archives culture, from the newly formed file collection, collation and the laws and regulations in the process of using, so as to provide a good environment for ${ }^{[8]}$. development and utilization of the archives information resources mainly from the following aspects: first, from the start of colleges, books archives management work on the equally important position with the task of teaching. Two are the key links of personnel training, will also be able to plan the whole order of the school is relatively effective. Therefore, managers should be in the library and archives work propaganda significance, will enhance the level of workers in the first place; secondly, library and Archives management work from the staff To enhance the degree of integration to start, not only to clear the contents of tasks and implementation guidelines of their own, but also to identify the archives value look relatively important. In order to make students clear looking for books and archives, archives workers can properties according to the age, the theme, reasonable arrangement, they will be marked with the serial number, and in accordance with the corresponding the position of the display; thirdly, the scattered work combined with centralized processing mode. The library and archives management work is divided into two parts: daily 
inspection and special analysis for Library and archives management of some common, mainly processed by the daily work of staff, they need to be responsible for classification in every day, Check and placement work. And for some special precious books and archives, the main person in charge of each department of the regular arrangement, to check the contents of the file, maintain the continuity and integrity.

\section{Strengthen the Innovation Consciousness of Rrchives Culture Edification}

The monographic study on archives, editing and publishing is an important way for the development of archival information resources. Through the compilation of archives information analysis, induction, processing, history, primitive, the dispersion of information into high specificity, practical information, providing targeted to use, and combined with the reality, targeted mining related information, the organization of thematic information compilation, the existing file information from potential to reality, scattered into focus, the development and utilization of the archives information resources from the now closed, semi closed type to the open type over ${ }^{[9]}$. in the information age, to Out of the compilation of routines, open innovation, pay attention to the local political, economic, cultural and other work process, around the local government center, focus and attention of the society, the social needs of the editor "era of" fast food "excellent", better service to the society. Give full play to the role of the patriotic education base archives through the exhibition, promotion of archival treasures and other measures to expand the connotation of education, providing educational establishments to citizens.

\section{Enhance the Consciousness and Ability of File Personnel}

We should strengthen the archives management personnel service consciousness, to develop data resources as a starting point, to encourage staff to understand the needs of customers through the network platform, and establish reasonable feedback and processing platform. Establish the consultation mechanism, the customer demand in the first place, the function of archives management of improvement around the customer requirements. The knowledge structure of personnel archives management work, actively organize staff training and learning skills in computer network, and has chosen to recruit new talent to master the modernization of archives management technology and computer network technology. In order to comprehensive development and utilization of the archives information resources, security The normal operation of the archives management network platform, promote archives management and improve the level of service.

\section{Deepen the Theoretical Research}

Vigorously promote the construction of Archives Culture inevitable request to deepen the theoretical research of Archival Science archives, expand the vision of the cultural construction, scientific construction of archives culture by the development of a series of problems, smoothly guiding the work of cultural construction archives ${ }^{[10]}$. through the research on the theory guiding practice with theory of archives culture, focusing on the theoretical basis, development and utilization of the archives information resources to maintain archives safety and improve the file resource sharing rate target, the use of personalized service, enhance the development of archives looking and predictability, so as to promote the development and utilization of archives resources.

\section{Conclusion}

To sum up, the construction of archive culture plays an irreplaceable role in the development and utilization of the archives information resources in the process of innovation, from promoting the use of archival resources, and enhance the consciousness of using the concept of archives staff resources, as well as in the utilization of archives laws and regulations play a positive role in the construction, so the construction of archive culture to a certain extent, can promote the development of information the archives and resource utilization efficiency, pay attention to the construction of archive culture, can promote the sustainable development of archives industry.

\section{References}

[1] Jing Yang . On cultural property of archives and strengthen the cultural construction of modern archives [J]. communication. 2016 (19): 225. 
[2] Ming Yang . Archives culture construction problems and Countermeasures of [J]. blue Taiwan 2016 home and abroad. (4): 40.

[3] Nan Zhou . Construction of enterprise archives culture innovation business office of [J]. (20) 12-13. 2016.

[4] Xianan Song. Archives of the cultural construction of the [J]. office business. 2014 (23): 68.

[5] Shenghui Ma. Personalized service on archives information [J]. Heilongjiang science and technology information. 2013 (5): 153.

[6] Shuyan Li. Under the environment of network archival information resources development and utilization of integrated [J]. Economic Research Guide. 2011 (34): 215-216.

[7] Fei Han. To achieve [J]. chizi reasonable utilization of archives information resources (MID). 2014 (11): 232.

[8] Na Xin. Exploitation and utilization of archives information resource effectiveness analysis [J]. Liaoning economy. 2010 (8): 95.

[9] Yuying Tang, Xiaoying Wen. Analysis of archival information resources development and utilization of archives in Beijing. 2010 [J]. (4): 34-35.

[10]Bin Jun. Perfecting the legal system to explore the development and utilization of cultural resources of archives of the [J]. business office, 2016 (19): 100. 